DOI 10.1515/LINPO-2016-0003

\title{
Metaphorical conceptualization of success in American success books, aphorisms and quotes
}

\author{
Jolanta Lącka-Badura \\ Foreign Languages Center, University of Economics in Katowice \\ e-mail: jolanta.lacka-badura@ae.katowice.pl
}

\begin{abstract}
The paper seeks to investigate how SUCCESS is conceptualized metaphorically in popular American success books, aphorisms and quotes. The study is based on an analysis of a corpus comprising over 600 utterances in which the lexical entry SUCCESS is regarded as constituting part of a metaphorical expression. The utterances have been extracted from the initial corpus of 10 success guide books, as well as 150 success aphorisms and quotes by famous Americans. The study investigates two aspects of this conceptualization. In the first instance, it examines which metaphorical source domains, as understood within the framework of Conceptual Metaphor Theory, prove to be most productive in the corpus. Secondly, in line with the frequently expressed views that the significance of conceptual metaphor as an explanatory construct is sometimes overstated in cognitive linguistic research, the paper attempts to analyze examples of linguistic metaphors which appear to be motivated in ways that are, at least in part, independent of well-established conceptual mappings, with particular emphasis on the resemblance-based and image metaphors associated with the predicate nominative forms ' $\mathrm{X}$ is a $\mathrm{Y}$ '.
\end{abstract}

Keywords: success; conceptual metaphor; metaphorical source domains; linguistic metaphors

\section{Introduction}

SUCCESS is one of the key concepts underlying the nature of American culture. It thus appears both interesting and worthwhile to investigate how it is conceptualized metaphorically in popular American success books, aphorisms and quotes, the text types being understood as 'words of wisdom' reflecting (at least to some degree) the attitudes to success in American culture.

Kövecses (2000) observes that, although there are many different conceptions of success in the United States, the prototypical understanding, functioning as the idealized conception of success, remains remarkably uniform; it is largely based on three major notions: the protestant work ethic, the 'American Dream', and the spirit of competition. "Success for most Americans means financial success. The idea is that if you have a lot of money, you are successful" (ibid.: 309). ${ }^{1}$ The prevalent belief is that if one's inner resources (talent, intelligence, goal-oriented attitude) are combined with the resources

${ }^{1}$ Cf. Marsden (1992). 
provided by America (the land of infinite possibilities), and if one only works hard, the success will eventually come. Along with the inner attributes and hard work, another important component of success is competition with others. "If you are smarter, stronger, more industrious, and so forth, than others, then you will be successful" (ibid.: 310). Further components are courage and the readiness to take risks, being dynamic and actionoriented, believing in the changeability of the future. This prototypical understanding of success in American culture is confirmed in numerous studies, foregrounding other components (beside hard work and goal-orientedness), such as sacrifice and self-denial (e.g. Robbins 2009), as well as indicating various measures of success, including independence and self-sufficiency (e.g. Mergel 2007).

Kövecses also observes that the description of American success is revealed through language in a number of ways; the spirit of competition, for instance, is widely reflected in the numerous sports metaphors, sport being "the primary domain in which success and failure are explicitly accepted and measured" (2000: 311). The goal-orientedness is expressed in the numerous take-constructions (take a bath, take a look at), occurring in American English significantly more frequently than in other varieties of English, showing preference for the have structures (have a bath, have a look at). The shifting of nouns into the category of verbs, as well as many 'innovations' with the -er ending (braburner, babysitter, go-getter) reflect the action-orientedness in American culture.

Investigating idiomatic creativity from the cognitive perspective, Langlotz (2006) presents a number of 'archetype metaphors' underlying our understanding of SUCCESS, PROGRESS and FAILURE. For instance, numerous idioms reflect the combination of the metaphors SUCCESS IS UP and HIGH STATUS IS UP with the metaphor DEVELOPMENT IS MOVEMENT ALONG A PATH TOWARDS A DESTINATION. Importantly, the idioms analyzed also indicate that upward movement often involves danger, and thus "the conceptualization of success as being high-up intrinsically entails the idea of latently lurking failure: if one is up, one can easily fall down" (ibid.: 162).

The present paper attempts to investigate the metaphorical conceptualization of SUCCESS reflected in American success books, aphorisms and quotes. Drawing on the Conceptual Metaphor Theory, the study focuses, in the first instance, on the metaphorical source domains that prove to be most productive in the text corpus. Secondly, the paper attempts to analyze and explain some instances of image/poetic metaphors which appear to be motivated in ways that are, at least in part, independent of stable and fixed metaphorical structures entrenched in our conceptual system.

\section{Theoretical background}

During the last decades the Conceptual Metaphor Theory (CMT) (Lakoff and Johnson 1980; Lakoff 1987, 1993; Lakoff and Johnson 1999) has become the dominant perspective on metaphor, influencing a vast array of studies in humanities and cognitive sciences. ${ }^{2} \mathrm{CMT}$

2 The theory is also widely referred to as the Conceptual Theory of Metaphor and Metonymy (CTMM). Yet, given that metaphor is central to the present study, the term Conceptual Metaphor Theory (CMT) will be used throughout the paper. 
can roughly be summarized as follows: metaphor is the main mechanism through which we comprehend abstract concepts and perform abstract reasoning; it is fundamentally conceptual, not linguistic, in nature, with metaphorical language being just a surface manifestation of conceptual metaphor; metaphor arises from mapping among different cognitive domains, especially the mapping from familiar, easily understood source domain onto unfamiliar, abstract target domain; ${ }^{3}$ such mappings are asymmetrical, partial, fixed sets of ontological correspondences between entities in a source domain and a target domain; they are not arbitrary, but grounded in our body movement, perception, everyday experience of physical and social character. The system of conventional conceptual metaphors is mostly unconscious, automatic, and used with no noticeable effort (Lakoff and Johnson 1993, 1999).

Lakoff and Johnson (1980) differentiate between three types of metaphors: i) structural metaphors, in which one concept is metaphorically structured in terms of another; ii) orientational metaphors which organize a whole system of concepts with respect to spatial orientation; iii) ontological metaphors, involving abstract concepts, emotions, ideas, processes, states, structures, being assigned "an object-like status" (Szwedek 2002: 163). CMT also acknowledges the existence of image or poetic metaphors, sometimes referred to as 'one-shot' metaphors, which are nonetheless viewed in CMT as using and building on the system of conceptual metaphors. Rather than mapping one conceptual domain onto another, often with many concepts in the source domain mapped onto many corresponding concepts in the target domain, image metaphors "function to map one conventional mental image onto another" (Lakoff 1993: 229). In other words, an image metaphor involves understanding one entity in terms of aspects/facets/attributes/properties of the perceptual experience associated with another.

The huge impact of CMT on humanities and cognitive sciences notwithstanding, the theory has (not infrequently) been criticized for its bold claims about language and human condition. Many critics of CMT argue that the reality of spoken and written discourse is far more complex, in terms of metaphorical thought patterns, than discovered by traditional CMT methods. Having acknowledged the great explanatory power of CMT, Gibbs (2013) indicates areas of skepticism about its empirical adequacy; concerns regarding the dangers involved in postulating mental constructs from linguistic evidence alone are also expressed by other scholars (e.g. Casasanto 2009; Fusaroli and Morgagni 2013; Gibbs and Perlman 2006; Koller 2006). A number of studies question both the stability and universality of embodied experience and its expression in image schemas and conceptual metaphors, viewing human experience as deeply social and shaped by cultural tradition, resulting in various possible interpretations of the same metaphorical expressions (Fusaroli and Morgagni 2013; Gibbs 2013). Ritchie proposes that "[h]ow any particular speaker intends a metaphor to be interpreted, and how any particular hearer does interpret the metaphor, can never be absolutely determined" (2003: 138). Some alternative con-

${ }^{3}$ Domain is defined by Langacker as "any sort of conceptualization: a perceptual experience, a concept, a conceptual complex, an elaborate knowledge system, etc." (1990: 3). Similarly, Dirven and Verspoor view domain as "any coherent area of conceptualization, such as meals, space, smell, color, articles of dress, the human body, the rules of football, etc., etc." (1998: 37). 
ceptual metaphors may be proposed, many of them seen as motivated by non-conceptual factors (Gibbs 2013). Another criticism arises from the claim made by many cognitive linguists that conceptual metaphors are comprehended 'automatically', which seems to indicate a view of language as a single, monolithic activity, disregarding the multitude of factors affecting people's in-the-moment comprehension of metaphorical language. Many linguistic discussions do not sufficiently acknowledge different levels of understanding that may operate during language interpretation, "ranging from slow, conscious interpretation of discourse to fast, unconscious processing of metaphorical meaning" (ibid.: 28).

Drawing on and often seen as an important complement to CMT, another widely applied approach to analyzing metaphor from the cognitive perspective is the Mental Space Theory and Conceptual Blending Theory, originally proposed by Fauconnier (1994). Conceptual integration (blending) consists in setting up networks of mental spaces that map onto each other and blend into new spaces in various ways (Fauconnier 1994; Fauconnier and Turner 1996, 2002; Jäkel 2003). Conceptual integration networks are used systematically in the online construction of meaning. Acknowledging the emphasis of the conceptual blending theory on multiple mental spaces in creating metaphorical mappings, and its attention to possible dynamic processes in online metaphor interpretation, critics question the view that such a wide range of phenomena claimed to exhibit conceptual integration arise from a single mechanism, one that does not render itself to empirical verifiability (Evans 2011, Gibbs 2013).

A relatively recent approach to understanding and interpreting figurative language is the Theory of Lexical Concepts and Cognitive Models (LCCM Theory) (Evans 2007, 2010, 2013; Zinken et al. 2008), treating the CMT as but one type of knowledge which is important in figurative language understanding. Unlike the two most influential theories of figurative language in cognitive linguistics, i.e. CMT and CBT, LCCM relates to frontstage cognition perspective, one that takes account of "how linguistic prompts signal which aspects of non-linguistic knowledge are activated in linguistically mediated meaning construction" (Evans 2010: 658). The view of lexical concepts facilitating (direct or indirect) access to the conceptual system via a number of association areas ${ }^{4}$, seems to bear a strong resemblance to the fundamentals of frame semantics, with its view of words activating or invoking frames of semantic knowledge relating to the specific concepts (Fillmore 1982, 1985; Fillmore and Baker 2010).

According to the proponents of LCCM, CMT fails to explain many instances of figurative language use, particularly certain classes of image/poetic metaphors, not motivated by recurring and ubiquitous correlations in experience, in which symmetrical/bidirectional relationships between target and source domains can be traced, as well as the predicate nominative constructions ' $\mathrm{X}$ is a $\mathrm{Y}$ ' that have been traditionally studied in the literary tradition and the philosophy of language. While the metaphorical expression Sally is a block of ice may be motivated by the conceptual metaphor INTIMACY IS

${ }^{4}$ See Evans $(2007,2010)$ for the partial cognitive model profile for the lexical concept [FRANCE], providing (direct and indirect) access to a range of cognitive models. 
WARMTH, examples such as Juliet is the sun, Achilles is a lion, or My boss is a pussycat are less clear (Evans 2013: 79-80).

Taking into account the great impact that Conceptual Metaphor Theory has had on different strands of research in cognitive sciences, as well as the criticisms it gave rise to among linguists and cognitive scholars, researchers increasingly acknowledge that different theories and approaches should be seen as fitting together and complementing each other, and thus advocate the use of multiple ways of studying metaphor (e.g. Gibbs 2013; Kövecses 2010; Ritchie 2003).

Following from the above, the main focus of attention is placed in the present paper on the metaphorical conceptualization of SUCCESS interpreted in line with the premises of the CMT theory, seen as providing an adequate and credible explanation for the phenomena analyzed. Additionally, an attempt is made to interpret selected instances of the ' $\mathrm{X}$ is a Y' metaphors related to SUCCESS, with a view to demonstrating their complex, unobvious and non-automatic nature, as well as the significance of the context in which the metaphors appear.

\section{Corpus and methods}

The initial sample is composed of two types of material. The first sub-corpus comprises 10 popular downloadable success guide books (or their extensive fragments) written by American authors at various points during the last 100 years. Some date to the beginnings of the $20^{\text {th }}$ century, regarded as 'success classics', others have been published in recent years. The second sub-corpus is composed of 150 popular success aphorisms and quotes by famous Americans, including, among others, writers and poets (e.g. Henry David Thoreau, Emily Dickinson), scientists (e.g. Thomas J. Watson), politicians (e.g. Colin Powell), civil rights activists (e.g. Jesse Louis Jackson), entrepreneurs (e.g. John D. Rockefeller), sports personalities (e.g. Vince Lombardi), actors and celebrities (e.g. Bill Cosby). All the quotes have been extracted from selections of aphorisms and quotes available on the Internet, and their popularity was assumed on the grounds of their repeated occurrence on several websites of this type (www.inspirational-quotes.info, www. brainyquote.com, www. worldofquotes.com). ${ }^{5}$ The books have been marked SB1 to SB10, according to the date of their first publication, while all the aphorisms and quotes have been grouped together in the sub-corpus marked AQ. ${ }^{6}$

5 The definitional aspects of aphorism, as well as the latter's distinctiveness among sentences/maxims/ quotes, is not viewed as relevant for the present study (cf. Forajter 2009; Morson 2006). Both aphorisms and quotes constituting the corpus under investigation are treated as 'words of wisdom' reflecting (at least to some degree) the attitudes to success and failure in the American sphere.

$\begin{array}{ll}6 \text { SB1 (Success Book 1) W. Walker Atkinson (1907) The Secret of Success } \\ \text { SB2 } & \text { W. W.Wattlers (1910) The Science of Getting Rich } \\ \text { SB3 } & \text { N. Hill (1928) The Law of Success } \\ \text { SB4 } & \text { N. Hill (1937) Think and Grow Rich } \\ \text { SB5 } & \text { W. Stone and N.Hill (1960) Success through a Positive Mental Attitude } \\ \text { SB6 } & \text { T.Gambordella (1994) O.m.a. Obsessive Mental Attitude: The Ultimate } \\ & \text { mental Secret of Success }\end{array}$


Although the concept of SUCCESS may be linguistically realized in a variety of forms making use of various lexical units such as ACHIEVEMENT or ACCOMPLISHMENT, the decision has been made to limit the final corpus to sentences including at least one occurrence of the lexical item SUCCESS, with a view to providing a tentative proposal of the core metaphoric structure of the concept as realized in success books, aphorisms

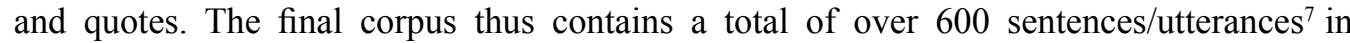
which the lexical item SUCCESS is regarded as constituting part of a metaphorical expression. The Metaphor Identification Procedure (MIP) proposed by the Pragglejaz Group (2007) has been applied to check the metaphoricity of the lexical units comprising the lexical entry SUCCESS. Even if the subjective criteria have not been entirely eliminated, they have at least been limited to increase the reliability of the analysis. The main focus is on the qualitative analysis of the example utterances, with quantitative measures used mostly to determine whether and to what degree certain metaphors contribute to the patterns recurrent in the corpus and may thus be deemed significant. ${ }^{8}$

The paper seeks to investigate, in the first instance, the metaphorical conceptualizations of SUCCESS reflected in American success books and quotes within the Conceptual Metaphor Theory, focusing on the metaphorical source domains which prove to be most productive. Secondly, in line with the more critical views postulating that CMT, albeit extremely influential, is not the only relevant approach to metaphorical language and thought, the paper attempts to analyze examples of the metaphorical use of predicate nominative constructions ' $\mathrm{X}$ is a $\mathrm{Y}$ ' that appear to be motivated in ways that are, at least in part, independent of well-established conceptual mappings.

\section{Findings and discussion}

\subsection{Conceptual metaphors}

The analysis performed within the framework of Conceptual Metaphor Theory has demonstrated that SUCCESS is metaphorically conceptualized in a variety of ways, encompassing structural, orientational and ontological metaphors reflecting our everyday experience.

The most often found conceptualization is the projection of SUCCESS as DESTINATION (DESIRED LOCATION AT THE END OF A PATH/ROAD), a component of the

SB7

SB8

SB9

SB10
D.S. Kennedy (1998) The Ultimate Success Secret

L. Pierce (2002-2005) 19 Secrets of Super Success. How to Master the Conscious and Unconscious Habits that Could Make You a Super Success

C. Guillebau (2009) 279 Days to Overnight Success

R. Sharma (2011) Little Black Book for Stunning Success

7 The distinction between sentence and utterance (see e.g. Evans 2007) is not deemed significant for the present analysis and thus the terms are used interchangeably in the paper.

${ }^{8}$ Instances where metaphors comprising the lexical item SUCCESS appear repeatedly as part of the title quoted throughout the text of a book (e.g. SECRET OF SUCESS) have been counted as a single utterance in the analysis. 
overarching event structure metaphor based on the preconceptual SOURCE-PATH-GOAL scheme: ACHIEVING SUCCESS is structured in terms of REACHING THE END OF A PATH (cf. Lakoff et al. 1991; Langlotz 2006). The quotes below exemplify the metaphor SUCCESS is DESTINATION (DESIRED LOCATION AT THE END OF A PATH/ ROAD):

1. Many a man has gone a very long way toward success, only to stumble and fall, ... (SB3)

2. Every failure is a step to success. (AQ, William Whewell)

3. The road to success may be, and generally is, obstructed by many influences which must be removed before the goal can be reached. (SB3)

4. The road to success is always under construction. (AQ, Lily Tomlin)

5. Let's begin by accompanying Bill McCall of Sydney, Australia on a journey from failure and defeat to success and achievement. (SB5)

6. Failure is... the highway to success. (AQ, Og Mandino)

7. ... finding that our failures were but friendly guide-posts that led us onward and upward to success. (SB3)

The following set of correspondences emerge from the above utterances:

- Pursuing success corresponds to a journey: approaching/moving forward towards the end of a path (SUCCESS);

- Progress towards success corresponds to forward movement;

- Actions undertaken in order to achieve success and events occurring in pursuit of success correspond to stages on a path;

- Effort required to achieve success corresponds to effort required to move along a path;

- Difficulties faced when trying to achieve success correspond to obstacles on a path;

- Achieving success corresponds to reaching the end of a path;

- Success corresponds to a destination (desired location at the end of a path).

As can be seen in (7), there is a strong connection between the SOURCE-PATHGOAL scheme and VERTICALITY; in line with the observations made by Langlotz (2006) in relation to idiomatic expressions, the structural metaphor ACHIEVING SUCCESS IS REACHING THE END OF A PATH is often combined with the understanding of SUCCESS in terms of LOCATION UP/HIGH; following from that, pursuing SUCCESS is projected not only as active horizontal movement along a path towards a destination, but also as vertical movement UPWARDS. This conceptualization is illustrated in the following quotes:

8. Success is how high you bounce when you hit bottom. (AQ, George Smith Patton)

9. ... the jobs he took and the investments he made in climbing from failure to success are not important here. (SB5)

10. ... Frank better raised himself from failure to success by employing Benjamin Franklin's plan. (SB5)

The above mapping being very strongly reflected in the corpus, there are, however, quotes contradicting this conceptualization, indicating that the very pursuit of a desirable outcome is synonymous with SUCCESS: 
11. Success is a journey not a destination. The doing is often more important than the outcome. (AQ, Arthur Ashe)

Interestingly, many quotes comprising the metaphors: SUCCESS IS DESTINATION (LOCATION AT THE END OF A ROAD/PATH) and ACHIEVING SUCCESS IS REACHING THE END OF A PATH do not confirm the traditional/definitional conceptualizations of SUCCESS and FAILURE viewed as antonyms. In (5) FAILURE is conceptualized as the beginning of (or a stage in) a journey towards SUCCESS, whereas in (2) it is one of the 'steps' leading to SUCCESS. The positive role that FAILURE plays in pursuit of SUCCESS is even more evident in (6) and (7); in the former, FAILURE not only leads to SUCCESS, but enables to reach if faster (highway to success), and in the latter FAILURES are the friendly guideposts showing us the right direction towards SUCCESS. ${ }^{9}$

The corpus comprises numerous quotes in which the understanding of SUCCESS is structured by our experiences with physical and living entities, giving rise to a variety of ontological metaphors. The most productive source domain for the concept of SUCCESS is the domain of PHYSICAL OBJECTS, viewed by Szwedek $(2011,2014)$ as the most common and the ultimate source domain. SUCCESS (as projected in the corpus under study) is frequently 'objectified' (cf. Szwedek 2002, 2011, 2014); it can be produced, brought, obtained, created, quantified, etc. The quotes below exemplify the metaphor SUCCESS IS A PHYSICAL OBJECT:

12. ... using the 17 success principles is the ONLY known method of producing success. (SB6)

13. I know that a negative attitude toward others can never bring me success. (SB4)

14. Attitude and the ability to obtain wealth and success by following the principles of PMA. (SB8)

15. Success and joy and inner peace don't just show up. You need to create them. (SB10)

16. Eighty percent of success is showing up. (AQ, Woody Allen)

While the conceptualization of SUCCESS as a PHYSICAL OBJECT seems rather clear in (12), (14), (15) and (16), one may wonder whether the SUCCESS brought in (13) is perhaps projected as a human. However, linguistic expressions stating that any kind of attitude can bring me someone (e.g. a sister, a wife, a friend) seem less acceptable than expressions stating that an attitude can bring me something (e.g. money), thus the conceptualization of SUCCESS as an OBJECT appears more plausible. ${ }^{10}$

Within the domain of PHYSICAL OBJECTS, the most frequently encountered conceptualization is that of SUCCESS understood in terms of a BUILDING or STRUCTURE, for which foundations need to be laid and which is constructed using appropriate

9 The finding that the definitional understanding of SUCCESS and FAILURE does not capture the entire extent of these two concepts is corroborated in other studies (see e.g. Lącka-Badura 2015).

${ }^{10}$ Nonetheless, the corpus comprises instances of quotes, e.g. Nothing can bring you success but yourself. (SB3), which do not render themselves to such a straightforward interpretation, making the allocation of the metaphors to particular domains (PHYSICAL OBJETS or HUMANS) more problematic. 
building materials; endurance is the desired attribute of the structure, it has a threshold and doors that can be opened with a key. The latter conceptualization also underlies the structural metaphor ACHIEVING SUCCESS IS OPENING THE DOOR (TO A BUILDING) WITH A KEY. Sometimes the doors are guarded (by dragons), as the building conceals something valuable. The metaphor SUCCESS IS A BULDING/STRUCTURE is revealed in the following utterances:

17. ACCURATE THINKING is one of the important foundation stones of all enduring success. (SB3, CAPITALS original)

18. So, if you are standing on the threshold of success without being able to pass over, ... (SB5)

19.... when the materials that go into success are plentiful and cheap. (SB3)

20. An erect head enables one to walk past the dragons at the door of Success. (SB6)

21. If you are reading novels or listening to music in your car, you are missing out on a major key to success. (SB8)

Besides being understood in terms of a BUILDING concealing something valuable, SUCCESS is often conceptualized as a PRECIOUS HIDDEN OBJECT; ACHIEVING SUCCESS is thus seen as FINDING A PRECIOUS OBJECT as a result of a long search:

22. ... but some there are who will want to go higher up the ladder, in search of success. (SB3)

23. Perhaps you failed because there was something more that was needed to bring you the success you were seeking. (SB5)

24. And no human being can ever find authentic success without the help of people. (SB10)

It is worthy of note that the above instances, particularly (22), can be viewed as elaborations of the earlier discussed mapping PURSUING SUCCES IS VERTICAL MOVEMENT TOWARDS A DESTINATION. Searching for success is combined here with moving higher up the ladder. The PRECIOUS OBJECT is sometimes locked in a container (a safe), meaning that ACHIEVING SUCCESS is understood as unlocking a container, reaching into it, and taking out the treasure:

25. A missing number for a correct, winning combination for success. (SB5)

An interesting sub-metaphor of SUCCESS IS A PHYSICAL OBJECT is the conceptualization of SUCCESS as a COMMODITY, for which one has to pay a price; the currency in the transaction is honest effort, hard work, dedication, devotion:

26. To be willing to pay the price of success in honest effort. (SB3)

27. I know the price of success; dedication, hard work and an unremitting devotion to the things you want to see happen. (AQ, Frank Lloyd Wright)

28. Hard work is the price we must pay for success. I think you can accomplish anything if you're willing to pay the price. (AQ, Vince Lombardi) 
A large group of the ontological metaphors views SUCCESS as a LIVING ENTITY CAPABLE OF MOVEMENT, both deliberate/intentional and incidental, for example:

29. Most success springs from obstacle and failure. ... (AQ, Scott Adams)

30. Success usually comes to those who are too busy to be looking for it. (AQ, Henry David Thoreau)

Importantly, as shown in (29), the fact that success springs again reinforces the dynamic vertical aspect of the conceptualization.

A very frequently occurring variant of the above is the metaphor SUCCESS is a HUMAN BEING/(a PERSON); it possesses typically human attributes (shyness, greed, acquisitiveness, meanness, egotism, self-interest, heroism), has parents, relatives and friends, it is also capable of typically human activities (to seduce, to teach, to fail). The quotes below exemplify this conceptualization:

31. Nothing fails like success. (AQ, Gerald Nachman)

32. Success is a lousy teacher. It seduces smart people into thinking they can't lose. (AQ, Bill Gates)

33. Success is shy - it won't come out while you're watching. (AQ, Tennessee Williams)

34. Successes have many fathers, failures have none. (AQ, Philip Caldwell)

35. And those traits we detest, sharpness, greed, acquisitiveness, meanness, egotism and self-interest, are the traits of success. (AQ, John Steinbeck)

Another variant of the ontological metaphor SUCCESS is a LIVING ENTITY is the mapping conceptualizing SUCCESS as a LIVING ORGANISM, usually a PLANT which has roots and grows from a seed, as seen in the following examples:

36. EVERY FAILURE BRINGS WITH IT THE SEED OF AN EQUIVALENT SUCCESS. (SB 4, CAPITALS original)

37. Both the successes and the failures have their roots in simple experiences. (SB3)

38. THINK well before you speak because your words may plant the seed of either success or failure in the mind of some other person. (SB3, CAPITALS original)

A very productive source domain within the group of ontological metaphors is the domain of FOOD, where the importance and pleasure of eating as a bodily experience shapes our understanding of SUCCESS. The examples below exemplify this mapping:

39. Success is sweet, the sweeter if long delayed and attained through manifold struggles and defeats. (AQ, A. Bronson Alcott)

40. Success is counted sweetest by those who ne'er succeed. (AQ, Emily Dickinson)

$41 . .$. we attract big and generous portions of success (SB5)

42. Notice that none of the man we have been talking about had success handed to him on a platter (SB5)

43. Whether you call it your purpose, mission, vision, ultimate goal, or by any other name, your desire is an absolutely vital ingredient to your success. (AQ, Bob Burg)

44. Failure is the condiment that gives success its flavor. (AQ, Truman Capote) 
In the above quotes SUCCESS is conceptualized as FOOD; one of its attributes is sweet taste, normally associated with pleasure and satisfaction. Quotes (39) and (40) clearly remind us of situations when, after being hungry for a long time, we enjoy the well tasting food to a greater degree than in situations when we were not so hungry. Understanding SUCCESS as FOOD is confirmed in other quotes, where it has some distinct flavor (intensified by FAILURE), it comes in portions, can be handed on a platter, and its preparation requires the use of specific ingredients.

SUCCESS is also pictured in terms of a complex SUBSTANCE which (again) requires ingredients; rather than being mixed at random, it is created according to a special formula:

45. The most important single ingredient in the formula of success is knowing how to get along with people. (AQ, Theodore Roosevelt)

46. Formula for success: under promise and over deliver. (AQ, Tom Peters)

A large group of metaphors in the corpus are grounded in the domain of PHYSICAL and/or MENTAL ACTIVITY. The following quotes exemplify how SUCCESS is conceptualized in terms of doing, getting, developing, focusing, trying, etc.:

47. Success is getting what you want; happiness is wanting what you get. (AQ, Dale Carnegie) 48. Success is focusing the full power of all you are on what you have a burning desire to achieve. (AQ, Wilfred Peterson)

49. Success is the doing, not the getting; the trying, not the triumph. (AQ, Zig Ziglar)

50. Success is the development of the power with which to get whatever one wants...

Although the domains of PHYSICAL and MENTAL activities are rather uneven in scope, it is often hard to draw a clear demarcation line between them, particularly when the ACTIVITY is ORGANIZED (e.g. a GAME) and/or COMPLEX. As shown in the examples below, SUCCESS may require rules (which seems to emphasize the mental aspect); it can also be trained and practiced, like many other activities, both physical and mental:

51. I think success has no rules, but you can learn a great deal from failure. (AQ, Jean Kerr)

52. Success must be continually practiced, or ... (SB5)

53. I have the privilege, as a success coach, to work with... (SB10)

Finally, a very frequently occurring mapping is the understanding of SUCCESS in terms of a sophisticated CONCEPT, SCIENCE or AREA OF KNOWLEDGE that can be defined, studied, researched and theorized upon; principles and laws pertaining to it may be formulated and taught, as seen in the following examples:

54. With that definition of success in mind, here's a few notes on what I DON'T do: ... (SB9, CAPITALS original)

55. ... to study, research, and find the simple, underlying principles of success. (SB5)

56. The Law of Success course epitomizes the philosophy and the rules of procedure ... 
57. Each new employee received an inspirational lecture course teaching him the fundamentals of success. (SB5)

58. Study success. (SB8)

A variant of the above is the conceptualization of SUCCESS as SECRET/MYSTERIOUS KNOWLEDGE, reflected in the numerous quotes comprising the linguistic expression 'the secret(s) of success', constituting the most frequently occurring 'success phrase' in the corpus.

\subsection{Interpretation of selected ' $\mathrm{X}$ is a $\mathrm{Y}$ ' metaphors}

Similarly to other types of discourse, the linguistic metaphors ' $\mathrm{X}$ is a $\mathrm{Y}$ ' occur in the corpus under study considerably less frequently than other types of metaphors. The majority of them may be convincingly explained and interpreted within the framework of Conceptual Metaphor Theory, seen as extensions of experientially grounded primary metaphors showing clear mappings from the more concrete to the more abstract domains. Yet there are instances of the predicate nominative structures ' $\mathrm{X}$ is a $\mathrm{Y}$ ' found in the sample which do not seem to lend themselves to such straightforward interpretations. Let's consider the following two quotes:

59. What is success? It is a toy balloon among children armed with pins. (AQ, Gene Fowler) 60. Success is the one unpardonable sin against our fellows. (AQ, Ambrose Bierce)

Within the framework of CMT, (59) may convincingly be interpreted as an image metaphor, an extension of the conceptual metaphor SUCCESS is a FRAGILE THING/ OBJECT, with weakness and fragility viewed as the specific properties mapped from the more concrete source domain onto the more abstract target domain. Just like a toy balloon may easily be damaged with as little as the touch of a pin, so can SUCCESS be destroyed by a slight mistake on the part of the success holder, or seemingly insignificant actions performed by others. However, as this conceptualization appears to evoke a functional rather than perceptual correspondence, it also appears to lend itself to an interpretation in terms of resemblance metaphors (cf. the analysis of the metaphor My boss is a pussycat in Evans 2010). A single feature of TOY BALLOONS, i.e. fragility/weakness, can plausibly be seen as being attributed to the abstract concept of SUCCESS. Thus, SUCCESS is not necessarily understood in terms of being a TOY BALLOON, but rather in terms of exhibiting a specific property of TOY BALOONS (cf. Szwedek 2011, 2014).

Moreover, a closer look at the quote confirms the prime significance of context in the interpretation of metaphors; it is the surrounding context of the utterance SUCCESS IS A TOY BALLOON that enables the relatively quick and 'automatic' interpretation of the metaphor SUCCESS IS A TOY BALLOON as an extension of the underlying conceptual metaphor SUCCESS IS A FRAGILE OBJECT; without the accompanying picture of children armed with pins (with which the toy balloon may easily be destroyed), the linguistic concept [TOY BALLOON] encoded by the form a toy balloon can also facilitate (direct or indirect) access to other cognitive models and association areas. By way of example, a TOY BALLOON, similarly to other TOYS, can also be understood as 
something of little value or importance, bought or received (although often not needed) for amusement, just a small imitation or representation of something bigger and real. Mapping such conceptualization onto SUCCESS, a different interpretation (guided by the selection of a particular cognitive model) emerges: SUCCESS is just a simplified representation of real life which may bring temporary joy and pleasure but should not be taken seriously. Another potential area of association that the concept [TOY BALLOON] facilitates access to is that of small brightly colored ornaments used for decorating parties and social events. With this in mind, we may view SUCCESS as but an ornament rendering life more beautiful and attractive.

Similarly to (59), quote (60), Success is the one unpardonable sin against our fellows, does not appear to be easily interpreted within the framework of CMT. Firstly, conceptual metaphor is generally understood as the projection of basic/familiar experiential structure from more concrete domains of experience to more abstract target domains. Assuming that the level of 'concreteness' an 'abstraction' of a domain can be determined by considering the ontological status of the component elements of the domain, with 'more abstract' domains having fewer elements of physical ontology (see Szwedek 2014), the concept of SIN may be viewed as being equally or more abstract than the concept of SUCCESS; it thus seems rather hard to imagine understanding SUCCESS in terms of SIN. Although the mappings from one abstract domain onto another abstract domain, and from a more abstract domain onto a more concrete domain, have been accounted for in research within the framework of CMT, metaphors of the latter type are particularly hard to find (see e.g. Jäkel 2003). With a relatively high level of abstraction for both concepts, understanding the relationship between SUCCESS and SIN is far from automatic, probably requiring at least some intellectual effort on the part of the interpreter. Moreover, one cannot exclude the possibility of a bidirectional relationship between the two domains (cf. Evans 2013). If, for instance, a young man raised in a Catholic family, where premarital sex is considered a SIN (i.e. behavior against the laws of God), boasts in front of his peers about his first sexual experience, the youths are highly likely to interpret their friend's SIN as a sort of achievement.

Importantly, SUCCESS is not obviously and evidently associated with SIN; conceptualizing SUCCESS as, for example, a BLESSING, may not come automatically, yet the access route to such a model would probably be relatively short. By contrast, picturing SUCCES as a SIN involves a rather long access route and thus exhibits a high degree of figurativity (cf. Evans 2010). Taking into account the primary cognitive model of SIN as an action or type of behavior against the laws of God and religious rules, one would need to think for a while to figure out how achieving success might be seen as an offense against God, a conception that seems particularly odd in American culture and thus far from 'automatic'. Perhaps the access route to the alternative model of SIN understood as a great fault, a highly reprehensible action or behavior, is slightly shorter, provided that one has the awareness of the possibility that for some people the success of others may cause suffering, thus in this sense succeeding may be viewed as doing our fellows 'harm'. Yet the access route becomes longer, requiring the activation of a greater number of cognitive models in order to facilitate interpretation, if we take into account the whole utterance; success being the one unpardonable sin against our fellows suggests that one 
person's success may be perceived as so offensive and so unbearable to others that it cannot be forgiven. There is obviously bitter irony in the statement, revealing the sad truth about our human nature, an observation that does not make the interpretation process less complicated. All things considered, the mapping of the structure of the abstract domain of SIN onto the (perhaps less) abstract domain of SUCCESS does not seem to make the latter easier to grasp.

\section{Concluding remarks}

The present paper has sought to investigate how SUCCESS is conceptualized metaphorically in American success books, aphorisms and quotes. In the first instance, the analysis focused on the metaphorical source domains, as understood within the framework of Conceptual Metaphor Theory, in an attempt to establish the domains that prove to be most productive in the corpus under study. The findings indicate that the vast majority of metaphors identified are relatively stable, entrenched, asymmetric, automatically processed cross-domain mappings grounded in our everyday experience and stored in our long-term memory, allowing us to understand more abstract concepts in terms of the more concrete ones. The scheme that appears to be the most frequently occurring mapping found in the sample is the conceptualization of SUCCESS as DESTINATION (DESIRED LOCATION AT THE END OF A PATH/ROAD), a component of the overarching event structure metaphor based on the preconceptual SOURCE-PATH-GOAL, with the concept of ACHIEVING SUCCESS structured in terms of REACHING THE END OF A PATH. This mapping is often combined with the pursuit of SUCCESS being conceptualized as vertical movement UPWARDS, and SUCCESS itself thus understood in terms of LOCATION UP/HIGH. The corpus also abounds in ontological metaphors, where SUCCESS is conceptualized in terms of PHYSICAL OBJECTS, primarily complex BUILDINGS or BUILT STRUCTURES, PRECIOUS HIDDEN OBJECTS (sometimes locked in a container), pricey COMMODITIES. A large group of the ontological metaphors view SUCCESS as a LIVING ENTITY CAPABLE OF MOVEMENT, with the variant metaphor SUCCESS is a HUMAN BEING/(a PERSON), possessing typically human attributes and capable of typically human activities. SUCCESS is also projected as a LIVING ORGANISM, usually a PLANT. Very productive source domains within the group of ontological metaphors are the domains of FOOD and (complex) SUBSTANCES. A large selection of metaphors in the corpus are grounded in the domain of PHYSICAL or MENTAL ACTIVITY. Finally, a very frequently occurring mapping is the understanding of SUCCESS in terms of a sophisticated CONCEPT, SCIENCE or AREA OF KNOWLEDGE, with the variant conceptualization of SUCCESS as SECRET/MYSTERIOUS KNOWLEDGE.

The paper has also attempted to analyze examples of linguistic metaphors associated with the predicate nominative forms ' $\mathrm{X}$ is a $\mathrm{Y}$ ' (SUCCESS is a $\mathrm{Y}$ ) that appear to be motivated in ways that are, at least to some degree, independent of well-established conceptual mappings. The lexical items forming the linguistic metaphors studied may be viewed as facilitating access to different cognitive models and associations areas, giving rise to a number of possible interpretations, with the extensions of conventional, experi- 
entially grounded conceptual metaphors constituting but one of the potential explanations. Those different interpretations are often mediated by the context, as well as by the interpreter's individual knowledge, experience and intuition. Additionally, the examples of the ' $\mathrm{X}$ is a $\mathrm{Y}$ ' metaphors analyzed also suggest the possibility of mappings from more abstract to less familiar domains, as well as bidirectional rather that asymmetric correspondences. Processing and understanding some possible conceptualizations may thus require significant intellectual effort, confirming that figurativity should be seen as a complex phenomenon.

\section{References}

Casasanto, D. 2009. When is a linguistic metaphor a conceptual metaphor ? In Evans, V. and S. Pourcel (eds.), New directions in cognitive linguistics, 127-145. Amsterdam and Philadelphia: John Benjamins Publishing Company.

Coulson, S. 2006. Conceptual blending in thought, rhetoric, and ideology. In Kristiansen, G., M. Achard, R. Dirven and F.J. Ruiz de Mendoza Ibáñez (eds.), Cognitive Linguistics: Current applications and future perspectives, 188-208. Berlin: Mouton de Gruyter.

Dirven, R. and M. Verspoor. 1998. Cognitive exploration of language and linguistics. Amsterdam and Philadelphia: John Benjamins Publishing Company.

Evans, V. 2007. Towards a cognitive compositional cemantics: an overview of LCCM theory. In Magnusson, U., H. Kardela and A. Glaz (eds.), Further insights into semantics and lexicography, 11-42. Lublin: Wydawnictwo UMCS.

Evans, V. 2010. Figurative language understanding in LCCM theory. Cognitive Linguistics 21 (4). 601-662.

Evans, V. 2013. Metaphor, lexical concepts and figurative meaning construction. Journal of Cognitive Semiotics $\mathrm{V}$ (1-2). 73-107.

Fauconnier, G. 1994. Mental Spaces: Aspects of meaning construction in natural language. Cambridge: Cambridge University Press.

Fauconnier, G. and M. Turner. 1996. Blending as a central process of grammar. In Goldberg, A. (ed.), Conceptual structure, discourse and language, 113-130. Stanford: Center for the Study of Language and Information.

Fauconnier, G. and M. Turner. 2002. The way we think. Conceptual blending and the mind's hidden complexities. New York: Basic Books.

Fillmore, C. J. 1982. Frame semantics. In Linguistics in the morning calm, 111-137. Seoul: Hanshin Publishing Co.

Fillmore, C. J. 1985. Frames and the semantics of understanding. Quaderni di Semantica 6. 222-254.

Fillmore, C. J. and C. Baker. 2010. A frames approach to semantic analysis. In Heine, B. and H. Narrog (eds.), The Oxford handbook of linguistic analysis, 313-340. Oxford: Oxford University Press.

Forajter, W. 2009. Wśród tropów i figur. In Barłowska, M., A. Budzyńska-Daca and P. Wilczek (eds.). Retoryka, 116-150. Warszawa: Wydawnictwo Naukowe PWN.

Fusaroli, R. and S. Morgagni. 2013. Introduction: thirty years after. Journal of Cognitive Semiotics V (1-2). $1-13$.

Gibbs, R.W. and M. Perlman. 2006. The contested impact of cognitive linguistic research on the psycholinguistics of metaphor understanding. In Kristiansen, G., M. Achard, R. Dirven and F.J. Ruiz de Mendoza Ibáñez (eds.), Cognitive linguistics: Current applications and future perspectives, 212-228. Berlin: Mouton de Gruyter.

Gibbs, R.W. 2013. Why do some people dislike conceptual metaphor theory? Journal of Cognitive Semiotics $\mathrm{V}(1-2) .14-36$.

Kristiansen, G., M. Achard, R. Dirven and F.J. Ruiz de Mendoza Ibáñez. 2006. Introduction: cognitive linguistics: current applications and future perspectives. In: Kristiansen, G., M. Achard, R. Dirven and F.J. Ruiz de Mendoza Ibáñez (eds.), Cognitive linguistics: Current applications and future perspectives, 1-17. Berlin: Mouton de Gruyter. 
Jäkel, O. 2003. Metafory $w$ abstrakcyjnych domenach dyskursu: Kognitywno-lingwistyczna analiza metaforycznych modeli aktywności umystowej, gospodarki i nauki. Kraków. UNIVERSITAS.

Koller, V. 2006. Of critical importance: using electronic text corpora to study metaphor in business media discourse. In Stefanowitsch, A. and S.T. Gries (eds.), Corpus-based approaches to metaphor and meton$y m y$, 237-266. Berlin: Mouton de Gruyter.

Kövecses, Z. 2000. American English. An introduction. Peterborough, Canada: Broadview Press.

Kövecses, Z. 2010. Metaphor (2 $2^{\text {nd }}$ edition). New York: Oxford University Press.

Krzeszowski, T.P. 1997. Angels and devils in hell. Elements of axiology in semantics. Warszawa: Wydawnictwo Energeia.

Lakoff, G. and Johnson, M. 1980. Metaphors we live by. Chicago: University of Chicago Press.

Lakoff, G. 1987. Women, fire, and dangerous things: What categories reveal about the mind. Chicago: University of Chicago Press.

Lakoff, J., J. Espenson and A. Schwartz. 1991. Master metaphor list (2 ${ }^{\text {nd }}$ edition). http://araw.mede.uic. edu/ alansz/metaphor/METAPHORLIST.pdf, (Accessed 2 May, 2012).

Lakoff, G. 1993. The contemporary theory of metaphor. In: Ortony, A. (ed.), Metaphor and Thought, 202-251. Cambridge: Cambridge University Press.

Lakoff, G. and M. Johnson. 1999. Philosophy in the flesh: the embodied mind and its challenge to western thought. New York: basic Books.

Langacker, R. 1990. Concept, image, and symbol. The cognitive basis of grammar. Berlin: Mouton de Gruyter.

Langlotz, A. 2006. Idiomatic creativity: A cognitive-linguistic model of idiom representation. Amsterdam/ Philadelphia: John Benjamins.

Łącka-Badura, J. 2015. Evaluation of success and failure in the Anglophone sphere: analysis of value-laden lexis in English-language aphorisms and quotes. In E. Krawczyk-Neifar (ed.), Continuity and change. To be continued..., 41-56. Katowice: Wyższa Szkoła Zarządzania Ochroną Pracy.

Marsden, M. 1992. The American myth of success: visions and revisions”. In: Nachbar, J. and K. Lause (eds.), Popular culture. An introductory text, 134-148. Bowling Green, OH: Bowling Green State University Popular Press.

Mergel, S.K. 2007. Making it in the world today: musings on the historical definition of success. http:// breadandcircusnetwork.wordpress.com/2007/10/20/ (Accessed 27 August, 2013).

Morson, G.S. 2006. Style: The rhetoric of aphorism. In Jost, W. and W. Olmsted (eds.), A companion to rhetoric and rhetorical criticism, 248-265. Oxford: Blackwell Publishing.

Pragglejaz Group. 2007. MIP: A method for identifying metaphorically used words in discourse. Metaphor and Symbol 22. 1-39.

Ritchie, D. 2003. ARGUMENT IS WAR - or a game of chess? Multiple meanings in the analysis of implicit metaphors. Metaphor and Symbol 18. 125-146.

Robbins, R.H. 2009. Cultural anthropology: A problem-based approach (5 ${ }^{\text {th }}$ edition). Belmont, CA: Wadsworth (Centage) Publishing.

Szwedek, A. 2002. Objectification: from object perception to metaphor creation. In Lewandowska-Tomaszczyk, B. and K. Turewicz (eds.), Cognitive Linguistics Today. 159-175. Frankfurt am Main: Peter Lang.

Szwedek, A. 2011. The ultimate source domain. Review of Cognitive Linguistics 9(2). 341-366.

Szwedek, A. 2014. The nature of domains and the relationship between them in metaphorization. Review of Cognitive Linguistics 12(2). 342-374.

Zinken, J., I. Hellsten and B. Nerlich. 2008. Discourse metaphors. In: Bernardez, E., R., R. F. Dirven and T. Ziemke (eds.), Body, language, and mind. Vol. 2: Sociocultural situatedness, 363-386. Berlin: Mouton de Gruyter.

\section{WEB sources}

http://www.inspirational-quotes.info

$\mathrm{http}: / /$ www.brainyquote.com

$\mathrm{http}: / /$ www.worldofquotes.com 